most requirements. Nuclear physicists will be particularly affected by the failure to consider particles of non-zero spin and observables other than crosssections, at a time when the proliferation of polarized sources has made asymmetry and triple scattering measurements commonplace. I know of no other work on this subject which can be read from end to end in a sensible time, however, and as such it is the most suitable book for a beginner.

V. R. W. EDWARDS

\section{Practical Thermodynamics}

Macroscopic Thermodynamics. By J. S. Turton. Pp. xvi+300. (Wiley: London and New York, April 1973.) £5.50 cloth ; $£ 2.95$ paper.

Here is an excellent introductory textbook on engineering thermodynamics to swell the contents of an already well stocked shelf. Of course, none of this classical material is new and the contents can be found in a number of other similar textbooks so it is inevitable that we should ask what the present author and printer together have achieved.

The strength of this textbook lies in a combination of the clarity of the author's style, his decision strictly to limit the contents to that part of thermodynamics which is relevant to the treatment of power cycles, refrigeration cycles and heat engines and to his inclusion of more than eighty fully worked examples in which both SI and British units are used. In addition more than 100 problems are included along with their answers so that a student who works carefully through the book will emerge with an ability to deal with a variety of both numerical problems and others requiring an understanding of the logic of thermodynamics.

The printing and layout are impeccable and the clean idealized diagrams give the book a real feeling of space, unlike some of its competitors which tend to be rather cramped. In order to achieve this open appearance in a book of this length some of the topics usually dealt with at this level have been omitted. There is no discussion of heat transfer by conduction, convection or radiation, nor is there any mention of the jet engine, although some of the principles involved appear in the chapter concerned with the combustion of fuels. The more recent technologies of direct energy conversion using semiconductors, MHD and fuel cells have also been omitted in order to give a more complete treatment of reciprocating machines.

Unexpectedly the International Prac- tical Temperature scale is described in some detail, while in the same chapter the diagram illustrating a thermocouple circuit makes the usual mistake of showing only one ice point junction, although two dissimilar metals are shown (for example, Pt-Pt, $\mathbf{R h}$ or Chromel-Alumel).

Nuclear fuels and solar energy are regarded as being outside the scope of the book, and it seems to look forward optimistically to an undiminished supply of fossilized fuels. When at last the supplies of these conventional fuels begin to decline how will the new textbooks on engineering thermodynamics respond?

Within the chosen range of contents the author has produced a first-class competitive textbook which will soon find a place in university mechanical engineering courses.

\section{J. C. Matthews}

\section{Lichen Alarm}

Air Pollution and Lichens. Edited by B. W. Ferry, M. S. Baddeley and D. L. Hawksworth. Pp. $\mathrm{x}+389$. (Athlone: London, April 1973.) $£ 6.25$.

THERE is a good deal to be said for using a biological method for estimating air pollution; and for this purpose lichens have certain advantages, such as their simple structure, slow growth, mainly airborne nutrition, and ability to absorb, passively, almost anything in air or water which comes in contact with the thallus. Thus, though resistant to harsh conditions of minimal nutrition, temperature, and water loss, most lichens are unusually sensitive to the accumulation of phyto-toxic materials.

These facts have been known to lichenologists for over a century, so it is perhaps surprising that this is the first book on the subject, but quantitative work has had to wait for the present flourishing condition of lichenology, and for the regular and widespread monitoring of at least one of the major air pollutants, namely sulphur dioxide. As might be expected, therefore, most of the book is concerned with $\mathrm{SO}_{2}$ and its effects. It is a collection of seventeen papers, mainly of a review type, by a total of nineteen authors, several of whom appear more than once. Most of them might be described as leading members of that very active body, the British Lichen Society, although three are from Canada, two from the USA, and one from Belgium.

After a short introduction by P. W. James, P. W. J. Saunders and C. M. Wood review at some length the production, dispersal and fate of $\mathrm{SO}_{2}$ in the environment. In those later chapters which deal with the recording and mapping of lichens, their distribution is assumed to relate to this one among the pollutants. Britain is probably better provided with recording gauges for $\mathrm{SO}_{2}$ than any other country (about 1,300 in 1968) and this has enabled British workers to devise two biological scales for estimating $\mathrm{SO}_{2}$ levels, which are already proving their worth. These are O. L. Gilbert's, based on bryophytes as well as lichens on several substrates, and Hawksworth and Rose's, which uses tree-bark lichens, both published in 1970. There are also in use several more complex, numerical indices of atmospheric pollution (IAP) or of poleotolerance $(P)$ devised in Belgium (De Sloover), Canada (LeBlanc et al.) and Estonia (Trass) but these do not seem to give more reliable results than the simpler British scales. Possibly Barkman's three lichen-based categories of light, moderate and heavy pollution for central Linburg (Belgium), which were used in planning the location of housing and industry, may be of the most practical use.

In chapter 7, B. J. Coppins sets aside the "drought hypothesis" of J. Rydzak; but though there is little doubt that "toxic gas" is the main influence, humidity is always an important local factor; and in the longest of several chapters on lichen physiology (chapter 12) J. F. Farrar sounds a note of caution, stressing the many variables, besides $\mathrm{SO}_{2}$ levels, which may affect the growth and survival of lichens.

Some of the other pollutantsfertilizers, sprays, weedkillers, radioactive nuclides, heavy metals, smokeare dealt with by $\mathbf{P}$. W. James in chapter 8 , but there is little or nothing known about the effects on lichens of ozone, $\mathrm{H}_{2} \mathrm{~S}$, or the car exhaust gases. There is one chapter by O. L. Gilbert on fluorides, which are increasingly used in industry, but we are told several times in the book that their effects are merely local, which seems doubtful, as no monitoring has been done except around a few smelters and so on in rural areas.

The historical changes in the lichen flora of England and Wales, outlined in chapter 16, give us an interesting picture of the growth of pollution; and the final chapter is a summary of the book, with suggestions for future work, for which, indeed, there is immense scope. There is a good index, and ample references at the end of each chapter. The editors might, perhaps, have pulled the collection together a bit more, but it is a pioneer work which is likely to remain essential not only for lichenologists but for the far wider readership of those who, nowadays, have an interest in the quality of the air we breathe.

C. G. DoBrs 